APRJ, Issue 1 (2014), pp 50-58

Short Report

\title{
"I Dislike my Body, I am Unhappy, But my Parents are not Disappointed in Me": Self-Esteem in Young Women with Dyslexia
}

\author{
Authors: Anna M. Dåderman ${ }^{1}$, Karolina Nilvang ${ }^{2}$, \& Sten Levander ${ }^{3}$
}

\begin{abstract}
Objectives: Strong self-esteem is related to good psychological health. Dyslexia has a negative effect on self-esteem, but this effect depends on support levels at home and/or school. Women with dyslexia are an under investigated group, and it has been suggested that female dyslexics should be given special attention from teachers with a view to improving their self-esteem. This paper set out to compare levels of self-esteem in women with dyslexia and normative women, and to investigate relationships between dyslexic problems and self-esteem.
\end{abstract}

Method: It was hypothesized that women with dyslexia would have a weaker selfesteem. We have assessed dyslexia, using a Swedish battery of standardised pedagogical, IQ, and neuropsychological tests, and the self-esteem of twelve young women (mean age 19 years; range 16-30), using a Swedish questionnaire that distinguishes between different dimensions of self-esteem (physical characteristics, talents and gifts, psychological health, relationships with parents and family, and relationships with others). Comparative ( $t$-tests) and correlational (Pearson's correlations and stepwise multiple regression analyses) statistical methods were performed.

Results: The study subjects had a weaker self-esteem than that of a normative sample of females $(N=313)$ in all dimensions, except for the dimension of relationships with parents and family. Spelling ability was related to "Physical characteristics" (negative) and to "Relations with parents and family" (positive). Moreover, speed of reading was related to "Psychological health" (positive).

Conclusions: The use of questionnaires that distinguish between different dimensions of self-esteem and a larger sample is recommended in future studies.

Keywords: Dyslexia; Self-esteem (Jag tycker jag är); Adolescent and young females.

Affiliations: ${ }^{1}$ Division of Psychology and Organizational Studies, Department of Social and Behavioural Studies, University West, SE 46186 Trollhättan, Sweden. E-mail: anna.daderman@hv.se ${ }^{2}$ TV4 Sverige AB, Division of Marketing and Advertising, SE 11579 Stockholm ${ }^{3}$ Faculty of Health and Society, Department of Criminology, Malmö University, SE 205 06 Malmö, Sweden. 


\section{Introduction}

Dyslexia can profoundly affect self-esteem (e.g., Riddick, Sterling, Farmer, \& Morgan, 1999; Singer, 2008) and consequently, life expectancy (Skinner, 2013), but the impact can be increased by a lack of diagnosis and lack of support. The present study was based on a general definition of self-esteem taken from Mead's role-taking theory (1934). Self-esteem involves not only a person's subjective interpretation of his or her own identity; it involves also how this subjective interpretation has been formed by the influence of the surroundings and interaction with these.

Those with dyslexia have a low self-esteem and try to protect or restore their vulnerable self-esteem in different ways, mostly by hiding, working hard, fighting back, or explaining their difficulties (Alesi, Rappo, $\&$ Pepi, 2012; Singer, 2008). These reactions are more intense if the person suffers from undiagnosed dyslexia (e.g., Edwards, 1994), leading to feelings of frustration, shame and loneliness (McNulty, 2003). Students with dyslexia are more withdrawn, more anxious and more depressed than matched controls (Dahle, Knivsberg, \& Andressen, 2011). A negative effect on self-esteem in persons with dyslexia may depend on support levels at home. Riddick (1996) identified self-esteem as a major concern in parents of children with dyslexia, because a poor or negative self-image could create a vicious circle of self-fulfilling prophecies. Inconsistent results have been reported regarding support at school. Some teachers are supportive, while others are not (Glazzard, 2010). Non-supportive teachers give those with dyslexia extra work at playtime, which resulted in the children missing the break. This led to them feeling isolated and left out. Supportive teachers treated those with dyslexia differently: by reducing the amount of text that the children were expected to produce, for example. Some teachers lack empathy and patience (Glazzard \& Dale, 2013), and some of them do not accept that dyslexia exists as a condition (Riddick; 1996; Undheim, 2003).

Women with dyslexia are a poorly studied group, and it was reported that females with dyslexia had a poorer psychological health (more symptoms of depression and anxiety) than did males with dyslexia (e.g., Nelson \& Gregg, 2012; Nolen-Hoeksema, 1990; Willcutt \& Pennington, 2000). Studies on dyslexia are often performed on men only or on samples with more men than women, and findings from such research are sometimes generalized to women. Men have dyslexia more often than women (2-3 times more often) - but this does not mean that women should not be studied. Alexander-Passe (2006) suggested that "female dyslexics should be given special attention from teachers with a view to improving their self-esteem" (p. 273). Evans, Flowers, Napoliello, \& Eden (in press) called for more research on specific vulnerability factors in women with dyslexia. In addition, self-esteem in young women only, is not often assessed by psychometric measures. We have therefore reported here results from a study among females with dyslexia using self-reporting instrument that distinguishes between different dimensions of self-esteem (physical characteristics, talents and gifts, psychological health, relationships with parents and family, and relationships with others). The following research questions were formulated:

- Are any dimensions of self-esteem weaker in young women with dyslexia compared with a normative sample of young women?

- Are there any relationships between dyslexic problems and dimensions of self-esteem in young women with dyslexia?

It was hypothesized that women with dyslexia would have weaker self-esteem.

\section{Method}

\section{Participants}

Selection criteria for inclusion in the study were as follows: (1) being selected by specialised teachers to have attainments below normal in literacy tests (a stanine value of 3 or lower); (2) both parents born in Sweden; 
(3) Swedish as mother tongue; and (4) to have taken Swedish compulsory education. The original sample comprised 15 women; all of them were assessed. From the original sample, those with no diagnosis of dyslexia $(n=3)$, according to the below specified criteria, were excluded from all further analyses.

The present study was targeted at 12 young women with dyslexia aged from 16 to 30 years $(M=18.9$ years; $S D=4.1 ; M d=17.5$ years $)$. All were undergoing some form of education: ten were studying at upper secondary school, while two were studying at an institute of higher education. Only two of the participants had previously been diagnosed as having dyslexia, while the remaining ten had not previously taken part in a dyslexia investigation.

All participants, or the parent or guardian of a participant under the age of 18 years, gave their written consent for participation. After completion of testing, participants were debriefed.

\section{Materials}

Dyslexia was assessed by our research team using individually administered standardized tests, taking into account the total number of years that a participant had attended school. We used a standardized Swedish test battery that was previously used to assess dyslexia (e.g., Dåderman, Lindgren, \& Lidberg, 2004; Jensen, Lindgren, Andersson, Ingvar, \& Levander, 2000). We assessed reading and writing skills using standardised tests (see the Methods, Table 1, for references). A diagnosis of dyslexia was confirmed if, in at least three reading and spelling tests out of four ${ }^{1}$, a subject achieved a score that lay more than one standard deviation unit below her highest score in one of two non-verbal intelligence tests.

The questionnaire Jag tycker jag är ("I consider myself to be", named also "I think I am") has been used to assess self-esteem (Ouvinen-Birgerstam, 1999). The test consists of 72 statements that measure how a person assesses himself or herself to lie in five aspects: physical characteristics such as appearance, body image or physical health (statements include, for example, "I like my body"), talents and gifts ("I find it easy to learn"), psychological health such as mental stability, mental strength, absence of anxiety and absence of aggression ("I am happy"), relationships with parents and family ("I feel loved at home"), and relationships with others such as peers and teachers ("I like my classmates", "My teachers are nice to me"). The test uses a four-point scale from which the test participant is to select one of: Accurate description, Reasonably accurate description, Poor description, False. Equal numbers of positive and negative statements, arranged in a random order, are used for each component of self-esteem. Normalisation values for the test are given in the manual for the test.

We have used an adult version of the questionnaire previously used in, for example, Jensen, Lindgren, Wirsén Meurling, Ingvar, and Levander (1999). Nilvang (2006) showed that the reliability, measured in term of internal consistency, its stability and construct validity, were good (e.g., Cronbach's alpha of the total scale was .91 and of the five dimensions it varied between .71 and .87). The factor structure and relationships with internationally established measures, when applied to 100 psychology students $(M=28$ years; $S D=7$; $81 \%$ females), were acceptable.

\section{Data processing and statistical analyses}

The raw data points in the dimensions of self-esteem were converted to stanine values using normative values for young females $(N=313)$, presented in the manual (Ouvinen-Birgerstam, 1999). One-sample $t$ -

1 The following four tests were used for assessment of dyslexia: decoding (23 words), spelling ( 25 words), speed of reading (Igellkotten or Båten), and word sequences (Jacobson, 1997). Other tests that were used to assess reading and writing skills were used for research purposes only. 
tests were used in order to compare mean raw scores in the dimensions of self-esteem in the participants with normative females. Further, we calculated $z$-points for the literacy and cognitive tests, in order to be able to compare the participants with normative stanine values (mean 5, SD 2) and $T$-values (mean 50, $S D$ 10), and to assess whether the results differed significantly from normative values.

Correlational analyses (Pearson correlation test and by a non-parametric correlation test Spearman rho for controlling of the age variable) were performed on raw scores, and data screening before analyses revealed that no significant outliers were present on raw scores. We then employed three separate multiple regression analyses, to explore the importance of the relationships. The small sample size allowed us to report only standardized beta and adjusted R-squared coefficients. The main analyses comprised statistical regression models (linear stepwise regression) (Tabachnick \& Fidell, 2012).

\section{Results}

\section{Investigation of dyslexia}

Twelve of the 15 study subjects satisfied the criteria set down by DSM-IV for dyslexia, while three of them did not. Table 1 summarises the results from the participants with dyslexia. The following analyses were based only on the sample of the 12 participants with dyslexia.

\section{Investigation of self-esteem}

The results obtained from the Jag tycker jag är test were compared with normative values. There was a significant difference in the self-esteem of the participants with dyslexia and normative values, revealed by the one-sample $t$-test. This difference was evident both in the total scale results $(t=3.62 ; p=.004)$, and in the subscales results $(t=2.72-4.39 ; p=.02-.001)$, except for the dimension of relationships with parents and family. The difference on this dimension was non-significant $(t=0.93 ; p=.37)$.

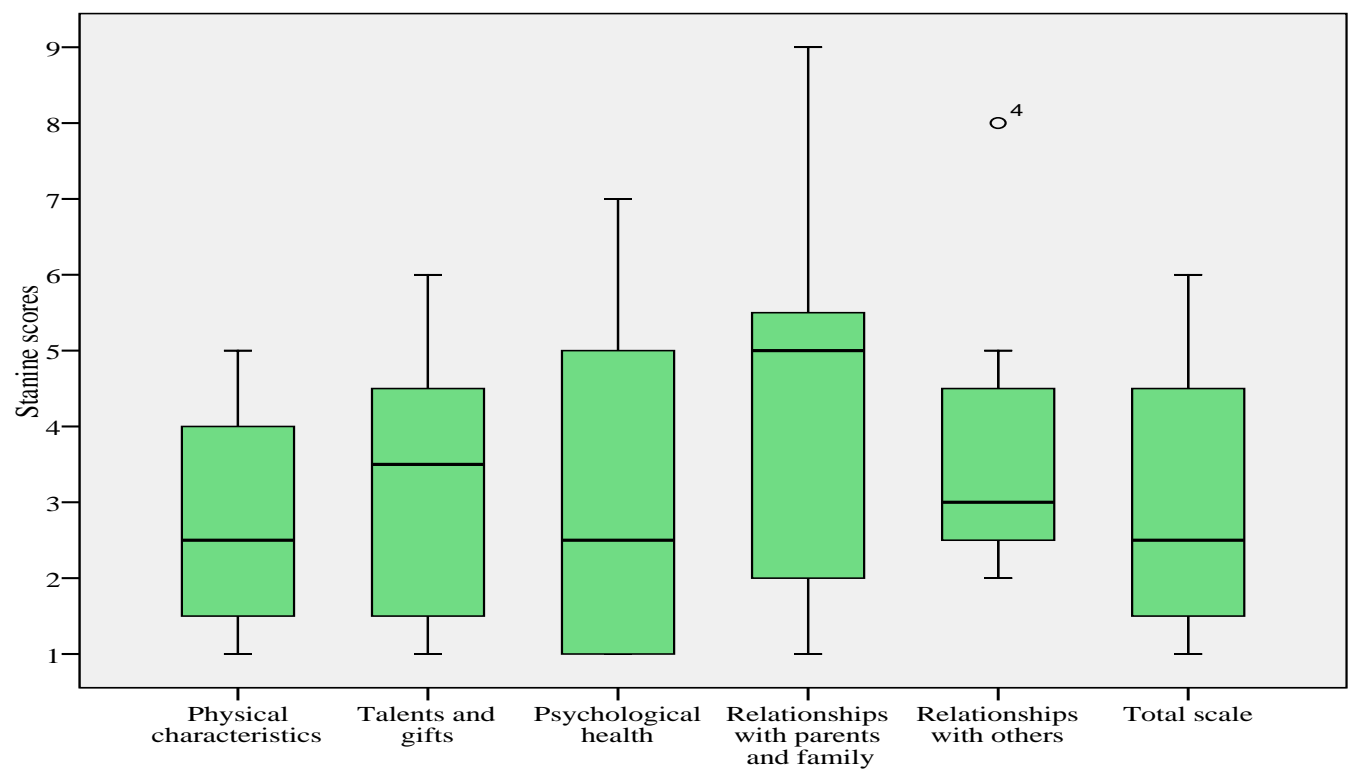

Figure 1 shows the stanine values for the participants with dyslexia for their results on the various dimensions in the Jag tycker jag är test.

Figure 1. Box plots for the Dimensions and the Total Scale in an Adult Version of the Test "Jag tycker jag är" (in English: "I Consider Myself to be") in a Group of 12 Dyslexic Young Women. The normative group comprised 313 young women (OuvinenBirgerstam, 1999). 
Table 1. Means (M), Standard Deviations (SD), Minimum (min) and Maximum (max) Values, z-scores (z), and Significance Level (p) for the Tests in the Study in a Group of 12 Dyslexic Young Women, using a Swedish Test Battery for Diagnoses of Dyslexia

\begin{tabular}{|c|c|c|c|c|}
\hline Test/measure (reference) & $M(S D)$ & $\min -\max$ & $\mathbf{z}$ & $p$ \\
\hline \multicolumn{5}{|l|}{ Structured interview (Dåderman et al., 2004, Appendix) } \\
\hline Decoding (Madison, 1996, Appendix 3) & $2.0(1.0)$ & $1-4$ & -5.20 & $<.001$ \\
\hline Spelling (Madison, 1996, Appendix 5) ${ }^{1}$ & $3.0(2.1)$ & $1-7$ & -3.47 & $<.001$ \\
\hline \multicolumn{5}{|l|}{ Reading ("Igelkotten") (Madison, 1998) } \\
\hline Speed & $4.6(1.7)$ & $3-7$ & -0.69 & .245 \\
\hline \multicolumn{5}{|l|}{ Reading (“Båten”) (Madison, 1998) } \\
\hline Comprehension & $5.4(1.9)$ & $3-8$ & 0.69 & .245 \\
\hline Speed & $5.8(1.5)$ & $3-8$ & 1.39 & .082 \\
\hline Word comprehension (Madison, 1996, Appendix 8) & $4.2(2.6)$ & $1-9$ & -1.39 & .082 \\
\hline \multicolumn{5}{|l|}{ Word sequences (Jacobson, 1997) } \\
\hline Words & $2.6(1.6)$ & $1-5$ & -4.16 & $<.001$ \\
\hline Letters & $2.3(2.2)$ & $1-8$ & -4.68 & $<.001$ \\
\hline \multicolumn{5}{|l|}{ Reading sequences (Jacobson, 2001) } \\
\hline Symbols & $2.5(1.4)$ & $1-5$ & -4.33 & $<.001$ \\
\hline Words & $3.7(1.6)$ & $1-5$ & -2.25 & .012 \\
\hline Sentences & $2.1(1.2)$ & $1-5$ & -5.03 & $<.001$ \\
\hline
\end{tabular}

Verbal learning and memory, Claeson-Dahl (Claeson, Esbjörnsson, Carlé, \& Wahlbin, 1971)

$$
\begin{array}{lll}
55.2(8.4) & 35-60 \quad 036
\end{array}
$$

A neuropsychological test, Rey Osterreith Complex Figure (Lezak, 1995)
Copy
$48.3(9.4) \quad 29-56$
$-0.59 \quad .278$
Memory
$49.6(7.6) \quad 33-58$
$-0.14 \quad .444$

Non-verbal IQ tests (Dureman \& Sälde, 1959)
$S R B-2$
$6.7(1.8) \quad 4-9$
$2.95 \quad .002$
$S R B-3$
$5.9(2.3) \quad 1-9$
$1.56 \quad .059$

Notes. Dyslexia was defined according to criteria set forth in the Diagnostic and statistical manual of mental disorders (DSM-IV; American Psychiatric Association, 1994, pp. 48-50) and the International classification of diseases (ICD 10; World Health Organization, 1992, p. 241). Values are given in stanine scores except for the Claeson-Dahl and Rey Osterreith Complex Figure tests; values in these tests are given in T-values. Stanine values between 3 and 6, and T-values between 40 and 60, are considered as a normal range. ${ }^{1}$ Short Version of 25 words was used. It was standardised on 341 junior college students by Selenius and Dåderman (in preparation); females had somewhat better spelling skill $(M=5.79$ spelling errors, $S D=3.3)$ than males $(M=6.58$ spelling errors, $S D=4.13)$ - the stanine value of 5 for 188 females corresponded to 6 errors). 


\section{Relationship between dyslexia and self-esteem}

A pattern of significant correlations became evident, with a negative correlation between the number of errors in spelling tests and self-esteem in the dimension of physical characteristics (-.64), and a positive correlation with self-esteem in the dimension of relationships with parents and family (.50). Feelings of selfesteem in the dimension of psychological health were positively correlated with speed of reading (.64), and non-verbal IQ (.67). These results motivated us to carry out relevant regression analyses. The correlations between the three dependent variables in the regression analyses are presented in Table 2. Table 2 shows that the dependent variables were not significantly related to each other. Table 3 presents the descriptive statistics and intercorrelations between independent variables in the regression analyses.

Table 2. Mean Values (M), Standard Deviations (SD), and Intercorrelations between the Dependent Variables in the Three Separate Regression Analyses in a Group of 12 Dyslexic Young Women

\begin{tabular}{cllll}
\hline Variable & $\boldsymbol{M}(\boldsymbol{S D})$ & $\mathbf{2}$ & $\mathbf{3}$ \\
\hline 1. & Spelling ability (wrong spelled words) & $9.50(3.92)$ & -.09 & -.10 \\
2. & Reading speed (words/min) & $112.85(21.05)$ & & .50 \\
3. & Non-verbal intelligence & $28.00(8.01)$ & & \\
\hline
\end{tabular}

Notes. Values are given in raw scores. The correlations were non-significant $(p<.05)$. A Short Version $(25$ words $)$ of the Madison's (1996) spelling test, and the Madison's (1996) reading test "Båten" (in English: The Boat), were used. Non-verbal intelligence was measured by the SRB-3 (Dureman \& Sälde, 1959).

Table 3. Mean Values (M), Standard Deviations (SD), and Intercorrelations between Dimensions in an Adult Version of the Test "Jag tycker jag är" (in English: "I Consider Myself to be") in a Group of 12 Dyslexic Young Women

\begin{tabular}{llllll}
\hline Dimensions of self-esteem & $\boldsymbol{M}(\boldsymbol{S D})$ & $\mathbf{2}$ & $\mathbf{3}$ & $\mathbf{4}$ & $\mathbf{5}$ \\
\hline 1. Physical characteristics & $1.25(8.26)$ & .20 & .44 & .15 & .51 \\
2. Talents and gifts & $-0.92(9.05)$ & & $.63^{*}$ & .32 & $.66^{*}$ \\
3. Psychological health & $-0.33(14.70)$ & & & $.58^{*}$ & .57 \\
4. Relationships with parents and family & $13.17(14.73)$ & & & & .46 \\
5. Relationships with others & $8.67(6.21)$ & & & &
\end{tabular}

Note. Values are given in raw scores. $* p<.05$.

The tolerance level for the measures was greater than .98 , and thus multicollinearity was not a problem. Table 3 shows that multicollinarity was not present.

The first stepwise multiple regression analysis with spelling ability (measured by the number of errors made) as the dependent variable showed that the variable "Physical characteristics" was entered first and explained $34.9 \%$ of the variance in spelling ability, $F(1,10)=6.90, p=.025$, beta $=-.64$. The variable "Relationships with parents and family" was entered second and explained a further $36.4 \%, F(1,9)=13.65, p=.005$, beta ("Physical characteristics") $=-.73$, beta ("Relationships with parents and family") $=.60 ; 71.3 \%$ of the variance in spelling ability was explained by these two dimensions of self-esteem, independently of the remaining dimensions (the analysis stopped at this point). A next multiple stepwise regression analysis with 
speed of reading as the dependent variable showed that $35.4 \%$ of the variance in reading ability (speed), $F$ $(1,10)=7.04, p=.024$, beta $=.64$, was explained by the dimension of psychological health. A final multiple stepwise regression analysis with non-verbal intelligence (SRB-3) as the dependent variable showed that the variable "Psychological health" explained $39.4 \%$ of the variance in non-verbal intelligence, $F(1,10)=8.15$, $p=.017$, beta $=.67$.

\section{Discussion}

The strength of the study was to assess self-esteem in adolescent and young women only using a questionnaire that distinguishes between different dimensions of self-esteem. Answering the first research question it was shown that young women with dyslexia had lower self-esteem than young women in the general population, except for self-esteem in the dimension of relationships with parents and family. Answering the second research question it was shown that low spelling ability was negatively related to "Physical characteristics" and positively related to "Relationships with parents and family", independently of the remaining dimensions of self-esteem. In addition, a higher self-evaluation of "Psychological health" was related to a higher speed of reading and to higher non-verbal intelligence, independently of the remaining dimensions of self-esteem.

Thus, young women with dyslexia had a considerably weaker self-esteem than the normative group of females, which is consistent with other studies including both females and males with dyslexia (e.g., Nalavany \& Carawan, 2012; Riddick, 1996). Poor self-esteem can be viewed as one facet of the emotional problems and other problems that are correlated with dyslexia (Humphrey \& Mullins, 2002); only few people see the challenge of living with dyslexia as a positive one (Folb, 2013; Singer, 2005). The self-esteem of young women with dyslexia was lower than that of the normative group on all dimensions except one: "Relationships with family", where the difference was non-significant. One way to strengthen self-esteem may be to refuse to accept, or at least to modify, the general attitude of others (teachers and peers) (see also Glazzard \& Dale, 2013): that any kind of failure is only a part of the life-long learning process experienced by all. It should, however, be acknowledged that this suggestion cannot be confirmed or denied by our results, because we have not investigated the attitudes of others to the women we have studied.

Common sense invites us to believe that negative feedback, particularly in a school situation that extends over more than a decade, and particularly without coming to understand one's reading and writing difficulties or receiving help in alleviating them, may result in weak self-esteem (McNulty, 2003; Palombo, 2001; Scott, Sherman, \& Phillips, 1992). Because our results indicated that family and not teachers and peers might play an important role in developing and maintaining a positive self-image in females with dyslexia, we agree with Bell (2013) and Prevett, Bell and Ralph (2013) that developing specialist teachers and assessors of students with dyslexia is needed. Dahle at al. (2011) pointed out that it is very important that teachers are able to identify different kinds of internalising problems (such as withdrawal from social activities, sadness/feelings of depression, loneliness, hopelessness and suicidal tendencies), because such problems are related to low self-esteem.

\section{Shortcomings of the study and some suggestions}

The narrowness of the sample studied here makes it difficult to generalise the findings. The low number of participants in the study makes it necessary to cross-validate the findings, and to determine, in particular, to what extent they can be generalised. A qualitative study might provide more depth against the results, and/or the tests would need to be replicated on a larger sample, which is recommended. The use of questionnaires that distinguish between different dimensions of self-esteem (such as psychological health) is recommended in studies of people with dyslexia. Our results showed that dyslexic people's problems were related to poor 
feelings of self-esteem in the dimension of psychological health, which may suggest a possibility of the existence of non-supportive peers and teachers.

\section{Implications for practice}

- Female students with dyslexia had weaker self-esteem in the dimensions of global self-worth, physical characteristics, talents and gifts, psychological health and relationships with others (such as teachers). Teachers should be helpful and empathic, give female students with dyslexia more attention and positive feedback, and develop their professional skills, awareness and knowledge of different learning styles of students with dyslexia.

- Lower spelling ability was related to lower self-evaluation of physical characteristics. Teachers and peers should engage with female students in order to become important others in shaping self-esteem in young women who spell poorly.

- High spelling ability and high performance in non-verbal IQ were associated with high self-esteem in the dimension of psychological health. Most young women with dyslexia in the present study were previously undiagnosed. Clinicians/assessors should investigate dyslexia in female students with low selfesteem.

\section{Acknowledgments}

Part of this research was a component of the second author's Bachelor's degree program in Psychology. We are grateful to the participants for volunteering their time and effort to complete the questionnaire and the tests required for the investigation. We thank University West for financial support to the first author for preparation of this article; and Dr. George Farrants for reviewing our English.

\section{References}

Alesi, M., Rappo, G., \& Pepi, A. (2012). Self-esteem at school and self-handicapping in childhood: Comparison of groups with learning disabilities. Psychological Reports, 111, 952-962.

Alexander-Passe, N. (2006). How dyslexic teenagers cope: An investigation of self-esteem, coping and depression. Dyslexia, 12, 256-275.

American Psychiatric Association (1994). Diagnostic and statistical manual of mental disorders (4th ed.) (DSM-IV). Washington, DC.

Bell, S. (2013). Professional development for specialist teachers and assessors of students with literacy difficulties/dyslexia: 'To learn how to assess and support children with dyslexia'. Journal of Research in Special Educational Needs, 13, 104-113.

Claeson, L.-E., Esbjörnsson, E., Carlé, B.-M., \& Wahlbin, M. (1971). Claeson-Dahls inlärningstest för kliniskt bruk [Claeson-Dahl's verbal learning test for clinical use]. Stockholm: Psykologiförlaget.

Dahle, A. E., Knivsberg, A-M., \& Andreassen, A. B. (2011). Coexisting problem behaviour in severe dyslexia. Journal of Research in Special Educational Needs, 11, 162-170.

Dureman, I., \& Sälde, H. (1959). Psykometriska och experimentalpsykologiska metoder för klinisk tillämpning [Psychometric and experimental methods for clinical application]. Stockholm: Almqvist \& Wiksell.

Dåderman, A. M., Lindgren, M., \& Lidberg, L. (2004). The prevalence of dyslexia and AD/HD in a sample of forensic psychiatric rapists. Nordic Journal of Psychiatry, 58, 371-381.

Edwards, J. (1994). The scars of dyslexia. Eight case studies in emotional reactions. London: Cassell.

Evans, T. M., Flowers, D. L, Napoliello, E. M., \& Eden, G. F. (in press). Sex-specific gray matter volume differences in females with developmental dyslexia. Brain Structure and Function, doi: 10.1007/s00429-013-0552-4.

Folb, N. (2013). Dyslexic writers and the idea of authorship. Journal of Writing in Creative Practice, 5, 125-139.

Glazzard, J. (2010). The impact of dyslexia on pupils' self-esteem. Support for Learning, 25, 63-69.

Glazzard, J., \& Dale, K. (2013). Trainee teachers with dyslexia: Personal narratives of resilence. Journal of Research in Special Educational Needs, 13, 26-37.

Humphrey, N., \& Mullins, P. (2002). Personal constructs and attribution for academic success and failure in dyslexia. British Journal of Special Education, 29, 196-203.

Jacobson, C. (1997). Manual ordkedjor [Manual for the Word sequences test]. Stockholm: Psykologiförlaget. 
Jacobson. C. (2001). Manual läskedjor [Manual for the Reading sequences test]. Stockholm: Psykologiförlaget.

Jensen, J., Lindgren, M., Andersson, K., Ingvar, D. H., \& Levander, S. (2000). Cognitive intervention in unemployed individuals with reading and writing disabilities. Applied Neuropsychology, 7, 223-236.

Jensen, J., Lindgren, M., Wirsén Meurling, A., Ingvar, D. H., \& Levander, S. (1999). Dyslexia among Swedish prison inmates in relation to neuropsychology and personality. Journal of the International Neuropsychological Society, 5, 452-461.Lezak, M. D. (1995). Neuropsychological assessment (3rd ed.). New York: Oxford University Press.

Madison, S. (1996). Läkande läsning och skrivning. En handbok om dyslexi [Remedial reading and writting. A handbook about dyslexia]. (2nd ed.). Angered: Tiden/Folksam.

Madison, S. (1998). Sommaren med Monika. Läsdiagnoser. Lärarhandledning och facit [Summer with Monica. Diagnoses of reading. A guide for teachers and test answers]. Lund: Madisons undervisningskonsult.

McNulty, M. (2003). Dyslexia and the life course. Journal of Learning Disabilities, 36, 363-381.

Mead, G. H. (1934). Mind, self and society. Chicago: University of Chicago Press.

Nalavany, B. A., \& Carawan, L. W. (2012). Perceived family support and self-esteem. The mediational role of emotional experience in adults with dyslexia. Dyslexia, 18, 58-74.

Nelson, J. M., \& Gregg, N. (2012). Depression and anxiety among transitioning adolescents and college students with ADHD, dyslexia, or comorbid ADHD/dyslexia. Journal of Attention Disorders, 16, 244-254.

Nilvang, K. (2006). Psykometrisk utvärdering av den modifierade versionen av självskattningsskalan Jag tycker jag är [Psychometric evaluation of the modified version of the test Jag tycker jag är (in English: I consider myself to be)]. M.Sc. Thesis. Department of Psychology, Stockholm University, Sweden.

Nolen-Hoeksema, S. (1990). Sex differences in depression. Stanford, CA: Stanford University Press.

Ouvinen-Birgerstam, P. (1999). Jag tycker jag är-manual [I consider myself to be - a manual] (2nd ed.). Stockholm: Psykologiförlaget.

Palombo, J. (2001). Learning disorders and disorders of the self in children and adolescents. New York: Norton.

Prevett, P., Bell, S., \& Ralph, S. (2013). Dyslexia and education in the 21 st century. Journal of Research in Special Educational Needs, 13, 1-6.

Riddick, B. (1996). Living with dyslexia. The social and emotional consequences of specific learning difficulties. London: Routledge.

Riddick, B., Sterling, C., Farmer, M., \& Morgan, S. (1999). Self-esteem and anxiety in the educational histories of adult dyslexic students. Dyslexia, 5, 227-248.

Scott, M. E., Sherman, A., \& Phillips, H. (1992). Helping individuals with dyslexia succeed in adulthood: Emerging keys for effective parenting, education, and development of positive self-image concept. Journal of Instructional Psychology, 19, 197-204.

Singer, E. (2005). The strategies adopted by Dutch children with dyslexia to maintain their self-esteem when teased at school. Journal of Learning Disabilities, 38, 411-423.

Singer, E. (2008). Coping with academic failure: A study of Dutch children with dyslexia. Dyslexia, 14, 314-333.

Skinner, T. (2013). Women's perceptions of how their dyslexia impacts on their mothering. Disability \& Society, 28, 81-95.

Tabachnick, B.G., \& Fidell, L.S. (2012). Using multivariate statistics. (6th ed.). New York, NY: Pearson Education.

Undheim, A. M. (2003). Dyslexia and psychosocial factors. A follow-up study of young Norwegian adults with a history of dyslexia in childhood. Nordic Journal of Psychiatry, 57, 221-226.

Willcutt, E. G., \& Pennington, B. F. (2000). Psychiatric comorbidity in children and adolescents with reading disability. Journal of Child Psychology and Psychiatry, 41, 1039-1048.

World Health Organization (1992). International classification of diseases, 10th Revision, Clinical modification (ICD10CM). Geneva: World Health Organization. 